\title{
Validity Test of Forecast Error of Wheat Yield through Non-Linear Growth Models in Bihar
}

\author{
Awdhesh Kumar ${ }^{1}$, Mahesh Kumar ${ }^{1 *}$, Mrinmoy Ray ${ }^{2}$, Avinash Kumar ${ }^{3}$, Shweta Kumari ${ }^{4}$ \\ and Piyush Kumar Bhargaw ${ }^{4}$
}

\author{
${ }^{1}$ Department of Statistics, Mathematics \& Computer Application, ${ }^{3}$ Department of Agril. \\ Extension, ${ }^{4}$ Department of Agronomy, RPCAU, Pusa, Bihar, India \\ ${ }^{2}$ IASRI, ICAR, New Delhi, India
}

*Corresponding author

\section{Key words \\ Non-linear growth models, Accuracy test, \\ Wheat yield, Forecasting of wheat \\ Article Info \\ Accepted: \\ 04 October 2018 \\ Available Online: \\ 10 November 2018}

\section{A B S T R A C T}

The present study has aimed to test the accuracy of Forecast error (FE) value of wheat yield through non-linear models in Bihar. For this study, there were four models namely Monomolecular, Logistic, Gompertz and Compound growth model has been taken under study. The best suitable non-linear model is selected on the basis of different statistic i.e. MAPE, RMSE, OSAF, \% FE. These were computed for various growth models under the three agro-climatic zones of Bihar and also for whole Bihar state. On the basis of these statistic Monomolecular model is best fit due to low value of MAPE, RMSE, OSAF and \% FE. Minimum \% FE found in case of monomolecular model in zone I, zone II, zone III and whole Bihar are $6.69 \%, 15.32 \%, 2.56 \%, 0.85 \%$ respectively. Whereas maximum \% FE are found in case of compound growth model in zone I, zone II, zone III and whole Bihar are $28.3 \%, 23.75 \%, 31.62 \%$ and $25 \%$ respectively. It was also found that the minimum $\% \mathrm{FE}$ in case of monomolecular model among all Zones including whole Bihar is $0.89 \%$ which is in complete Bihar condition. The low value of MAPE, RMSE, OSAF, \% FE also supported the validity test of forecast yield value of wheat in case of monomolecular model.

\section{Introduction}

India is famous as an agricultural country and this sector is major constituent of country's employment forces (about 52\% of total population). Majority of people are living in rural areas of this country who are directly or indirectly dependent on agricultural sector. Wheat is one of the most important cereal crops in India and a main source of vitamins and minerals such as thiamine, niacin, iron, riboflavin, calcium and fibre. It covers about $25 \%$ of the total global area. Consumption of wheat is directly proportional to the population growth.

Since our nation have large population and increasing decades-by-decades. Hence, increasing domestic demand owing to population growth should meet the future 
challenges of food and nutritional security. On this prospective for the planning purposes decision has to be made to invest accordingly for the short and long-term planning.

Due to increasing population the demand for wheat is increasing day-to-day. For future production and productivity of food grains in the country, Narain et al., (1984) used the regression approach whereas Ahuja et al., (1988) used Box-Jenkins time series models.

\section{Materials and Methods}

The present study is carried out to study of non-linear growth models of wheat yield in different agro-climatic zones of Bihar i.e. Zone-I, Zone-II, Zone-III and also for whole Bihar by the use of monomolecular model, logistic model, Gompertz model and compound growth model.

\section{Zone-1}

Saran, Siwan, Gopalganj, East-Champaran, West-Champaran, Muzaffarpur, Sitamarhi, Shiwhar, Vaishali, Darbhanga, Madhubani, Samastipur and Begusarai.

\section{Zone-2}

Saharsa, supaul, Madhepura, Purnia, Kishanganj, Araria, Katihar \& Khagaria.

\section{Zone-3}

Patna, Nalanda, Arwal, Bhojpur, Buxar, Bhabhua, Rohtas Gaya, Jahanabad, Nawada, Aurangabad, Munger, Sheikhpura, Lakhisarai, Jamui, Bhagalpur and Banka.

Time series wheat data were collected for the period from 1964-65 to 2015-16 from Directorate of Economics and Evaluation department Govt. of Bihar, Patna. The weather data were collected from Patna.

\section{Description of various non-linear growth models}

\section{Monomolecular growth model}

It denotes the productivity of wheat yields at time $\mathrm{t}$ and $\mathrm{c}$ be the ceiling value i.e. the maximum achievable value of $y$ in the long run (when $\mathrm{t}$ )

$\frac{d y}{d t}=b(c-y)$, Where $b(>0)$ is the rate of constant of growth pattern which in the present context depends upon a number of factors like economic condition, attitude of farmers, etc. Initial condition at $\mathrm{t}=1$, yield the solutions of the differential equation as

$\mathrm{Y}_{\mathrm{t}=\mathrm{c}} \mathrm{c}(\mathrm{c}-\mathrm{a}) \exp \cdot\{-\mathrm{b}(\mathrm{t}-1)\}+\mathrm{u}_{\mathrm{t}}$

\section{Logistic model}

Logistic model is appropriate in a situation where rate of growth is proportional to the product of the present size and the further amount of growth. That is

$\frac{d y}{d t}=b y(c-y)$, The solution of equation is

$\mathrm{Y}_{\mathrm{t}=\mathrm{c}} /[1+\mathrm{b} \exp \cdot\{-\mathrm{a}(\mathrm{t}-1)\}]+\mathrm{u}_{\mathrm{t}}$

\section{Gompertz model}

For Gompertz model.

$\frac{\mathrm{dy}}{\mathrm{dt}}=\operatorname{cylog}(\mathrm{a} / \mathrm{y})$

Integration above equation yields

$Y_{i}=a \exp [-b \exp \{-c(t-1)\}]$

\section{Compound growth model}

If $y_{t}$ denotes the observation (e.g. Wheat yield) at time $t$ and $r$ is the compound growth rate, model employed for estimating $r$ 
$\mathrm{y}_{\mathrm{t}}=\mathrm{y}_{0}(1+\mathrm{r})^{\mathrm{t}}$

\section{Criteria for selection of model}

The appropriateness of the model was judged by

Residual sum square (RSS)

Mean absolute Error (MAE) $=\sum_{\mathrm{t}=1}^{\mathrm{n}}\left|\mathrm{y}_{\mathrm{i}}-\hat{\mathrm{y}}_{\mathrm{i}}\right| / \mathrm{n}$

The smaller the value of MAE, the better is the model.

Root mean squared Error of (RMSE) RMSE is defined as

$\operatorname{RMSE}=\left(\sum_{\mathrm{i}=1}^{\mathrm{n}}\left|\mathrm{y}_{\mathrm{i}}-\hat{\mathrm{y}}_{\mathrm{i}}\right| / \mathrm{n}\right)^{1 / 2}$

The smaller the value of RMSE, the better is the model.

\section{One step ahead forecasting (OSAF)}

In this method the last year observation is not used in model building. The last value is predicted from the model and it is compared with the actual value. The percent forecast error is defined as:

$\% \mathrm{FE}=\frac{\frac{\left|\mathrm{y}_{\mathrm{i}}-\hat{\mathrm{y}}_{\mathrm{i}}\right|}{\mathrm{y}_{\mathrm{t}}}}{2100}$

Where, $\mathrm{y}_{\mathrm{t}}$ is the observed value and $\widehat{\mathrm{y}}_{\mathrm{i}}$ is the predicated value of the considered parameter at time (t). The smaller the value of $\% \mathrm{FE}$, the better is the model. Where summation is over all the observed values $y$ and ${\widehat{y_{i}}}$ respectively denote the observed and predicted value of wheat productivity and $\mathrm{n}$ denotes the total number of observed values (Kavalseth, 1985) in this model.
By the interpretation of Mean Absolute Percentage Error (MAPE), Mean Absolute Error (MAE), Percent Forecast Error (\%FE), One Step ahead Forecasting (OSAF), accuracy of fitted model for monomolecular model were tested and found to be must fitted among all models.

\section{Results and Discussion}

Forecasting technique used on the basis of non-linear growth models to forecast wheat yield in zone -1 , zone-2, zone- 3 and also in as a whole Bihar. The relevant data for the wheat yield period from 1964-65 to 2015-16 collected from directorate of economics and evaluation department, Government of Bihar, Patna. The weather data collected from meteorological division, Patna. The data for the year 1964-65 to 2014-15 were used for model development and remaining 2015-16 yield data were used for validation of forecast model. There were four mechanistic growth models were fitted i.e. Monomolecular, Logistic, Gompertz and Compound growth model.

The good suitable non-linear model is selected through different statistics MAPE, MAE, MSE and RMS was computed for various growth models under the three agro-climatic zones and also for whole Bihar state. The result has been shown in Table 1 to 4 . The model will be better if the value of Mean absolute percentage error (MAPE), Mean absolute error (MAE), Mean square error (MSE) and Root mean square error (RMSE) were low. The table from 1 to 4 supports that, after comparison from different non-linear growth model the value of MAPE, MAE, MSE and RMSE were low, in the case of Monomolecular non-linear growth model. It shows that monomolecular growth model were best fit model for wheat productivity in all three agro-climatic zones and also for complete Bihar. 
The randomness of residuals was tested by run test and the normality of the residuals were tested by Shapiro-wilk test. The value of $\mathrm{z}$ for zone- I are highly significant whereas zone II and zone III are significant which indicates the rejection of null hypothesis at $1 \%$ and $5 \%$ level of significance i.e. residual are not random. Whereas $\mathrm{z}$ value for complete Bihar are non-significant indicated the acceptance of null hypothesis at $5 \%$ level of significance i.e. the residuals are random. The Shapiro-wilk W statistic has been presented in table 2. The values are highly significant for zone I and for complete Bihar which indicates that nonfulfillment of normality assumption in the model whereas zone II indicates the acceptance of null hypothesis i.e. residual are normally distributed.

\section{Zone I}

After comparing with different growth models in zone I, Monomolecular model were found to be best fitted with comparison to logistic, Gompertz and Compound growth model. The run test doesn't support for the randomness assumption of the residuals but also normality of the residuals gets violated as it clear from the significant of the W- statistics of ShapiroWilk's.

Table.1 Randomness test for the residuals (Run test)

\begin{tabular}{|l|c|c|c|}
\hline Zone & No. of runs & Statistic & P-value \\
\hline$Z_{1}$ & 17 & $-2.572^{* *}$ & 0.01011 \\
\hline$Z_{2}$ & 19 & $-2.0004^{*}$ & 0.04546 \\
\hline$Z_{3}$ & 19 & $-2.0004^{*}$ & 0.04546 \\
\hline Bihar & 21 & $-1.2969^{N S}$ & 0.1947 \\
\hline
\end{tabular}

Table.2 Normality test for the residuals (Shapiro-wilks)

\begin{tabular}{|l|c|c|c|}
\hline Zone & D.F. & Statistic $(\mathbf{W})$ & P-value \\
\hline$Z_{1}$ & 50 & $0.93965^{* *}$ & 0.0119 \\
\hline$Z_{2}$ & 50 & $0.97558^{\mathrm{NS}}$ & 0.3712 \\
\hline $\mathrm{Z}_{3}$ & 50 & $0.9542^{*}$ & 0.04732 \\
\hline Bihar & 50 & $0.93233^{* *}$ & 0.006124 \\
\hline
\end{tabular}

$*=$ Significant at $5 \%, * *=$ Significant at $1 \%$

Table.3 Validity of forecast yield value under zone-I

\begin{tabular}{|l|c|c|c|c|}
\hline Statistics & Monomolecular & Logistic & Gompertz & Compound \\
\hline MAPE & 15.542 & 16.671 & 16.220 & 18.588 \\
\hline RMSE & 0.341 & 0.346 & 0.343 & 0.362 \\
\hline OSAF (Actual productivity = & 2.24 & 2.37 & 2.43 & 2.68 \\
\hline 2.09 t/ha) 2015-16 & & & & \\
\hline$\%$ FE & 6.69 & 12.5 & 15.17 & 28.3 \\
\hline
\end{tabular}


Table.4 Validity of forecast yield value under zone-II

\begin{tabular}{|l|c|c|c|c|}
\hline Statistics & Monomolecular & Logistic & Gompertz & Compound \\
\hline MAPE & 24.534 & 26.365 & 25.507 & 26.879 \\
\hline RMSE & 0.365 & 0.368 & 0.367 & 0.374 \\
\hline $\begin{array}{l}\text { OSAF (Actual productivity } \\
\text { = 2.61 tha) 2015-16 }\end{array}$ & 2.21 & 1.68 & 1.86 & 1.99 \\
\hline \% FE & 15.32 & 28.73 & 35.63 & 23.75 \\
\hline
\end{tabular}

Table.5 Validity of forecast yield value under zone-III

\begin{tabular}{|l|c|c|c|c|}
\hline Statistics & Monomolecular & Logistic & Gompertz & Compound \\
\hline MAPE & 21.838 & 26.885 & 25.004 & 31.774 \\
\hline RMSE & 0.275 & 0.288 & 0.283 & 0.373 \\
\hline OSAF (Actual productivity $=$ & 2.28 & 2.19 & 2.26 & 3.08 \\
\hline 2.34 t/ha) 2015-16 & & & & \\
\hline$\%$ FE & 2.56 & 6.41 & 3.57 & 31.62 \\
\hline
\end{tabular}

Table.6 Validity of forecast yield value of Bihar

\begin{tabular}{|l|c|c|c|c|}
\hline Statistics & Monomolecular & Logistic & Gompertz & Compound \\
\hline MAPE & 12.965 & 14.233 & 13.692 & 18.029 \\
\hline RMSE & 0.279 & 0.286 & 0.283 & 0.321 \\
\hline $\begin{array}{l}\text { OSAF (Actual productivity }= \\
\text { 2.24 t/ha) 2015-16 }\end{array}$ & 2.26 & 2.41 & 2.21 & 2.80 \\
\hline$\%$ FE & 0.89 & 7.58 & 1.39 & 25 \\
\hline
\end{tabular}

\section{Zone II}

Under this zone also monomolecular model has been found suitable in comparison with other models (Table 4).

The run test doesn't support the basic assumption of the model whereas shapirowilk support the basic assumption of model.

\section{Zone III}

Under this zone the randomness and normality assumptions of the model were not fulfilled (Table 1 and 2). The compound growth model very high \% FE while the MAPE and RMSE, for the monomolecular model lower than other non-liner growth models (Table 5).

\section{Bihar}

For complete Bihar the monomolecular model fits (Table 6). The run test supports the randomness while shapiro-wilk doesn't support the assumption of the normality of residuals.

The present study is based on non-linear growth model such as Monomolecular, Logistic, Gompertz and Compound Growth model. The utility of these models is that the provide insight into the under lying mechanism, III and complete Bihar has been developed and the result obtained through statistical software R, SAS 9.3 as well as RAUSTAT. The four models have been compared considering MAPE, RMSE, OSAF, $\%$ FE. On the basis of these statistics, 
monomolecular model has been found to be most appropriate suitable for describing the wheat productivity data after comparison among all the models and their fulfillment of assumption has been studied. After the analyzing the table number 3 to 6 it is found that monomolecular model has good accuracy by interpreting low OSAF, and \% FE, MAPE, RMSE. It is found that the \%FE is in Zone-I, Zone-II, Zone-III and for complete Bihar was $6.69 \%, \quad 15.32 \%, \quad 2.56 \%$ and $0.89 \%$ respectively.

\section{References}

Ahuja, D.L., Dey, A., Banerjee, A.K. and Raheja, S.K. (1988). A study of yield trends of wheat in India during last three decades. Annual Reports IASRI, New Delhi.
Kvalseth, T.O. (1985). Cautionary note about R2. The American Statistician, 39(4): 279-85.

Narain, P., Pandey, R.K. and Sarnp, S. (1984). Perspective for food grain production in 2000 A.D. Commerce, June 30, pp.879-883.

Pradip, K. N. and Krishna, K. G. (2002). Study on Growth Models: A Critical analysis with reference to Andhra Pradesh and India. Indian Agricultural Statistics Research Institute.

Prajneshu and Das, P.K. (2000). Growth models for describing state wise wheat productivity. Ind. J. Agril. Res., 34 (3): 179-181.

Venugopalan, R. and Shamasundaran, K.S. (2003). Non-linear Regression: A realistic modeling approach in horticultural crops research. J. Ind. Soc. Agric. Stat, 56(1): 1-6.

\section{How to cite this article:}

Awdhesh Kumar, Mahesh Kumar, Mrinmoy Ray, Avinash Kumar, Shweta Kumari and Piyush Kumar Bhargaw. 2018. Validity Test of Forecast Error of Wheat Yield through Non-Linear Growth Models in Bihar. Int.J.Curr.Microbiol.App.Sci. 7(11): 321-326.

doi: https://doi.org/10.20546/ijcmas.2018.711.040 